\title{
Dispersion of Butane in Vapex: The Effect of Drainage Height
}

\author{
Muhammad Imran, Simant R. Upreti* and Ali Lohi
}

Department of Chemical Engineering, Ryerson University, Toronto, Canada

\begin{abstract}
In this work, the dispersion of butane in heavy oil and bitumen is experimentally determined during the Vapex process with varying drainage heights. The experiments were performed at room temperature $\left(22^{\circ} \mathrm{C}\right) \mathrm{using}$ butane as solvent at the dew point pressure. We used cylindrical models with different heights varying from 15 to $45 \mathrm{~cm}$, packed with uniform mixture of heavy oil and glass beads. From the experiments, production rate dependency towards the drainage height is evaluated along with determination of butane gas solubility, live oil density, and viscosity. Conjugate gradient method is used to optimally determine concentration dependent dispersion coefficient as well as the solvent concentration at the solvent-oil interface by matching up experimental live oil production rates with ones predicted by model. A computational algorithm is developed to simultaneously solve process models of different heights, and optimally determine the corresponding dispersion coefficients.
\end{abstract}

Keywords: Vapex, butane, dispersion coefficient, heavy oil.

\section{INTRODUCTION}

Pioneered by Butler and Mokrys [1], Vapex or vapor extraction is a heavy oil recovery process relying on solvent injection to mobilize viscous oil reserves. In a Vapex operation, a light hydrocarbon solvent, or a solvent mixture is injected close to dew point conditions via a horizontal well inside the reservoir. Solvent absorption in heavy oil reduces its viscosity, and causes it to drain into an underlying horizontal production well from where the oil is pumped up to the surface. The use of solvents in Vapex obviates the energy requirements and environmental impacts that plague thermal recovery processes [2].

The heavy oil recovery from Vapex is due to the viscosity reduction and gravity drainage. The viscosity reduction results from the combined effects of molecular diffusion, convective motion, and surface renewal. Experiments have shown that rate of solvent transfer in porous media is much higher than that with diffusion alone $[3,4]$. The reason is dispersion, which is the combined effect of diffusion and convective motion. Dispersion not only depends on solvent concentration but also on drainage height $[5,6]$. To accurately predict the heavy oil recovery in a commercial Vapex application, it is therefore very important to know dispersion coefficients of various solvents.

Experimental results by Kapadia et al. [7], and El-Haj et al. [8] indicate the concentration dependence of solvent dispersion in Vapex. The researchers determined the linear variation of dispersion with solvent concentration in heavy oils. In Cold Lake bitumen, the dispersion of butane was found to be four orders of magnitude higher than the

*Address correspondence to this author at the Department of Chemical Engineering, Ryerson University, Toronto, Canada;

Tel: 14169795000 ext 6344; Fax: 1416979 5083;

E-mail: supreti@ryerson.ca molecular diffusion [7]. In a later investigation [8], thedispersion of butane was found for three different permeabilities in Athabasca oil. The dispersion coefficient for a lower permeability medium was observed to be slightly higher and this behavior was attributed to the increase in interstitial area with the decrease in the average size of glass beads packing in the porous medium. The goal of the present study is to examine the effect of drainage height on the dispersion of butane in Vapex. To this end, experiments are carried out with butane and heavy oil packed with glass beads in physical models of different drainage heights. Based on the experimental live oil production data and the process model, the dispersion coefficient of butane and its concentration at the solvent-heavy oil interface are optimally determined.

\section{EXPERIMENTAL SETUP}

Fig. (1) shows the experimental setup and flow diagram, which comprises a chlorinated poly vinyl chloride cylindrical pressure vessel of $55 \mathrm{~cm}$ height, and $15 \mathrm{~cm}$ internal diameter. The vessel is placed inside a water bath, and equipped with a load cell to suspend and track the weight of a cylindrical packing of heavy oil and glass beads. The vessel is connected to a source of butane, which is used to extract the oil from the packing. Temperature and pressure transmitters are provided for the vessel and the bath. A small funnel is provided at the bottom of the vessel to collect the produced oil and direct it to a calibrated collection tube of 25 $\mathrm{cm}^{3}$ capacity. At its downstream is a $50 \mathrm{~cm}$ long capillary tube of $0.1016 \mathrm{~cm}$ inside diameter. The tube is fitted with a differential pressure transducer to enable the determination of the oil viscosity. A $300 \mathrm{~cm}^{3}$ capacity heated stainless steel flash tank, and two acrylic water columns of 2,600 and 2,900 $\mathrm{cm}^{3}$ capacity help measure the amount of butane in the produced oil. 


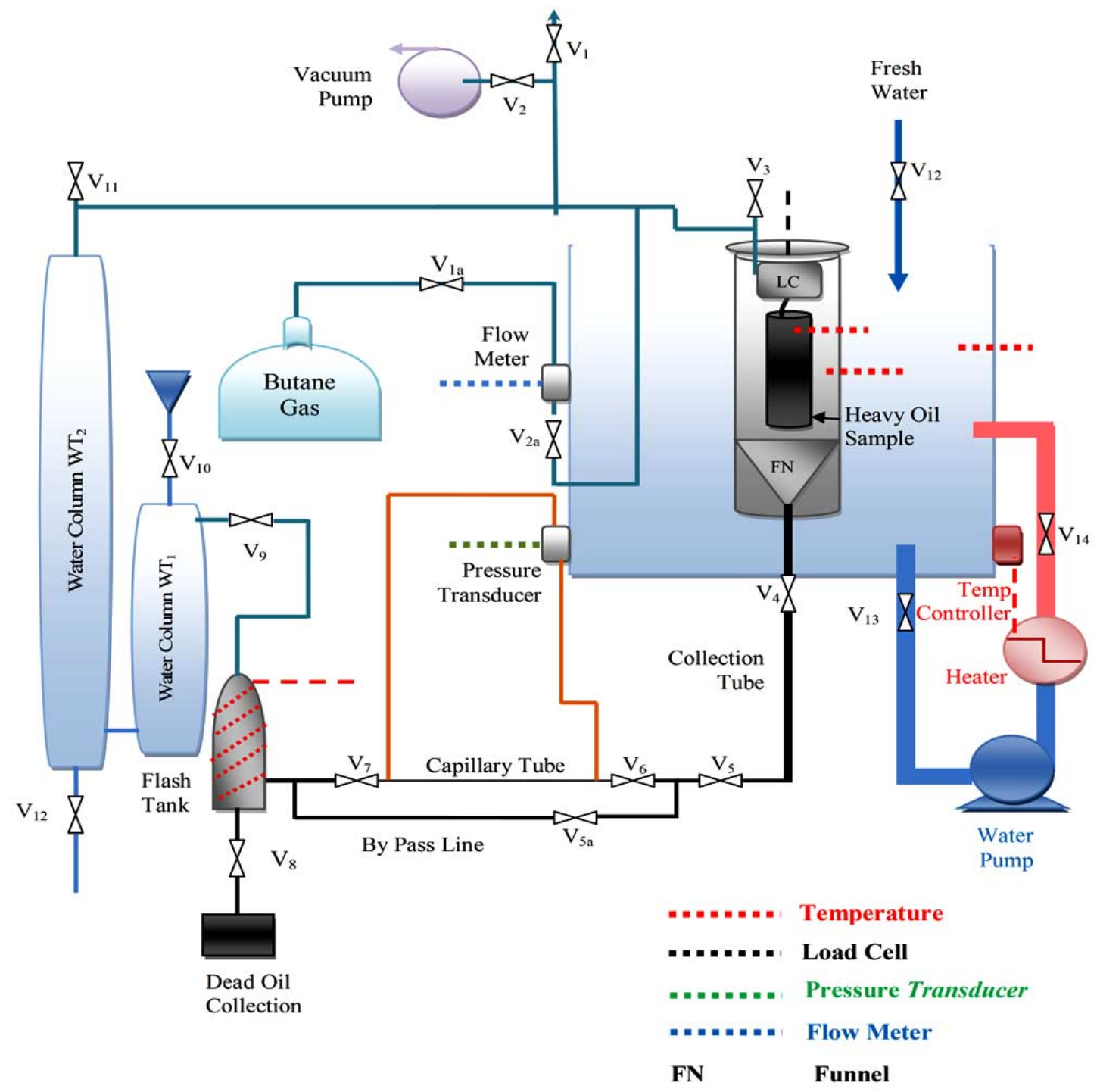

Fig. (1). Experimental setup and flow diagram.

\section{Preparation of the Physical Model}

A measured amount of the heavy oil supplied by Imperial Oil Canada (350 Pa.s viscosity, and $1,001 \mathrm{~kg} / \mathrm{m}^{3}$ density at room temperature and pressure) was collected in a pan and heated for 30 minutes at $70^{\circ} \mathrm{C}$. Glass beads of an average size of $360 \mu \mathrm{m}$ were gradually added in thin layers to the heated heavy oil. A new layer of beads was introduced after the older one had immersed into the mixture of heavy oil and beads. The procedure was repeated until the mixture became saturated with beads. This mixture was transferred to a cylindrical wire mesh of a given length and diameter to form a physical model for Vapex experiments. The model was then left in an air bath for 24 hours. In this manner, cylindrical physical models of $3 \mathrm{~cm}$ inside radius were prepared with lengths: $15,25,35$ and $45 \mathrm{~cm}$. Permeability value of $1.09 \times 10^{-10} \mathrm{~m}^{2}$, measured by El-Haj et al. [8] was used for the physical model. Porosity of the physical model was 0.38 based on the density and mass of the heavy oil and glass beads used in the preparation.

\section{Experimental Procedure}

Before starting an experiment, the pressure vessel was tested for any leakage. A vacuum pump was used to purge air from the setup. The initial pressure was $-15 \mathrm{mmHg}$ at the start of each experiment. The temperature of the water bath was set at the room temperature of $22^{\circ} \mathrm{C}$ and controlled with the help of a heat exchanger. By opening $\mathrm{V}_{1 \mathrm{a}}, \mathrm{V}_{2 \mathrm{a}}$ and $\mathrm{V}_{3}$ with rest of the valves closed, research grade butane of 99.99\% purity (MEGS Specialty Gases Inc., Montreal, Quebec) was injected into the vessel at the dew point pressure ( $\sim 30-31 \mathrm{psia})$ corresponding to a temperature 1$2{ }^{\circ} \mathrm{C}$ lower than the room temperature. To completely evacuate air from vessel, the vessel was filled with butane and vacuumed a couple of times. Finally, butane was introduced to the vessel to come in contact with the surface of the physical model suspended from a load cell. As butane penetrated the model, it reduced the viscosity of the heavy oil therein, causing it to drain out as live oil and accumulate in the funnel placed at the bottom of the pressure vessel. 
Valve $\mathrm{V}_{4}$ was opened to direct the diluted oil to the collection tube.

As soon as about $17 \mathrm{~cm}^{3}$ of live oil accumulated in the collection tube, the live oil was directed to the capillary tube and flash tank to determine the live oil viscosity and density, and butane solubility. This measurement was accomplished by opening the valves $\mathrm{V}_{5}, \mathrm{~V}_{6}, \mathrm{~V}_{7}, \mathrm{~V}_{9}$ and $\mathrm{V}_{11}$ with $\mathrm{V}_{8}, \mathrm{~V}_{10}$ and $\mathrm{V}_{5 \mathrm{a}}$ closed. Provision of bypass line to empty the collection tube in case of capillary tube clogging was in place. Valve $\mathrm{V}_{4}$ remained open throughout the viscosity determination experiment in order to maintain constant pressure. Live oil viscosity was calculated using Hagen-Poiseulle equation.

The live oil was then directed to the flash separation tank maintained at $70^{\circ} \mathrm{C}$. To ensure the proper flashing of the butane from the live oil, valve $\mathrm{V}_{9}$ was fully opened. The two water columns, $\mathrm{WT}_{1}$ and $\mathrm{WT}_{2}$, were filled with water up to desired mark before starting the experiment. As the butane gas from the flash tank moved towards $\mathrm{WT}_{1}$ the water level in $\mathrm{WT}_{2}$ increased. $\mathrm{WT}_{2}$ was scaled to calculate exact amount of water displaced from the separated gas. Proper operation of water displacement was assured by opening the valve $\mathrm{V}_{11}$ at the top of the $\mathrm{WT}_{2}$. After allowing sufficient time for the separation of butane from the live oil, valve $V_{10}$ was opened to release butane to the fume hood. Valve $\mathrm{V}_{8}$ was opened to collect the dead oil. In this way, oil production was carried out until almost $80-85 \%$ of the original oil in the physical model was extracted.

Knowing the amount of gas absorbed from water displacement as well as weight of the dead oil the solubility of butane gas and density of live oil was calculated using the following equations:

dissolved weight fraction of $\mathrm{C}_{4} \mathrm{H}_{10}=\quad$ weight of librated $\mathrm{C}_{4} \mathrm{H}_{10}$

live oil density $=\frac{\text { weight of librated } \mathrm{C}_{4} \mathrm{H}_{10}+\text { weight of dead oil }}{\text { volume of Live Oil }}$

The aforementioned steps were repeated timely during an experiment to calculate live oil viscosity, density and butane solubility. An ethernet data acquisition system with Labview 7 was used to monitor and record the following process variables: mass of the physical model, its temperature, temperature and pressure of the vapor chamber, flow rate and temperature of butane at the inlet, temperature of the water bath, pressure difference across the capillary tube, and temperature of flash tank.

\section{PROCESS MODEL}

In this section, a mathematical model is developed to describe the penetration of butane into heavy oils leading to the production of live oil in the aforementioned experiment. The main assumptions are as follows:

1. Temperature and pressure are constant.

2. The porous media of the physical model has uniform porosity and permeability.

3. The density of live oil remains constant during extraction process.
4. The dispersion of gas takes place along radial direction.

5. Dispersion of gas incorporates molecular diffusion, and the mixing effects such as surface renewal due to convection.

6. The velocity of gas-heavy oil mixture along $z$ direction is given by Darcy law. This velocity varies along the radial direction.

The unsteady state mass balance for solvent gas in a cylindrical differential element (Fig. 2) is given as:

$\frac{\mathrm{d}}{\mathrm{d} t}(\Delta V \phi \rho \omega)=[v \Delta \Delta \rho \omega]_{z+\Delta z}-[v \Delta A \rho \omega]_{z}+[J \Delta S]_{+\Delta}-[J \Delta S]_{r}$

where $\Delta V=2 \pi r \Delta r \Delta z$ is the volume of the element $\left(\mathrm{cm}^{3}\right)$, $\phi$ is the medium porosity, $\rho$ is the live oil density $\left(\mathrm{g} / \mathrm{cm}^{3}\right)$, $\omega$ is the mass fraction of butane in the medium, $\Delta A=2 \pi r \Delta r$ is the area $\left(\mathrm{cm}^{2}\right)$ transverse to the live oil velocity $v(\mathrm{~cm} / \mathrm{min})$ in the downward direction, and $\Delta S=2 \pi r \Delta z$ is the area $\left(\mathrm{cm}^{2}\right)$ transverse to the dispersive flux $J\left(\mathrm{~g} / \mathrm{cm}^{2} . \mathrm{min}\right)$ in the radial direction. Radial flux can be expressed by the Fick's first law of diffusion assuming $\rho \neq \rho(r)$ as:

$J=-D \rho \frac{\mathrm{d} \omega}{\mathrm{d} r}$

where $D$ is the undetermined concentration-dependent dispersion coefficient of butane in the porous medium and is considered to be a linear function of butane concentration in the medium, i.e.

$D=D_{0} \omega$

Previous studies [7-9] have shown this function to yield good agreement between the experimental and the modelpredicted output.

Taking the limits of $\Delta r$ and $\Delta z$ to zero in Equations (3), and using Equations (4) and (5), the mass transfer model is written as:

$\frac{\partial \omega}{\partial t}=\frac{D_{0} \omega}{\phi}\left[\frac{1}{r} \frac{\partial \omega}{\partial r}+\frac{\partial^{2} \omega}{\partial r^{2}}\right]+\frac{1}{\phi} \frac{\partial\left(D_{0} \omega\right)}{\partial \omega}\left[\frac{\partial \omega}{\partial r}\right]^{2}-\frac{1}{\phi}\left[v+\omega \frac{\partial v}{\partial \omega}\right] \frac{\partial \omega}{\partial z}$

In the above equation, $v$ is Darcy velocity given by

$v=\frac{K_{\mathrm{r}} K \rho \mathrm{g}}{\mu}$

where $K_{\mathrm{r}}$ is relative permeability of the medium, $K$ is the permeability $\left(\mathrm{cm}^{2}\right), \rho$ is the density of live oil $\left(\mathrm{g} / \mathrm{cm}^{3}\right), \mathrm{g}$ is gravity $\left(\mathrm{cm} / \mathrm{min}^{2}\right)$, and $\mu$ is live oil viscosity ( $\mathrm{g} / \mathrm{cm} . \mathrm{min}$ ). The following concentration-dependent viscosity correlation [9] was used:

$\mu=\mu_{0} \omega^{-2}$

Using Equations (7) and (8), Equation (6) can be written as:

$\frac{\partial \omega}{\partial t}=\frac{D_{0} \omega}{\varphi}\left[\frac{1}{r} \frac{\partial \omega}{\partial r}+\frac{\partial^{2} \omega}{\partial r^{2}}\right]+\frac{D_{0}}{\varphi}\left[\frac{\partial \omega}{\partial r}\right]^{2}-\frac{K_{r} K \rho g \cos \theta}{\mu_{0} \varphi} \frac{\partial \omega}{\partial z} 3 \omega^{2}$ 


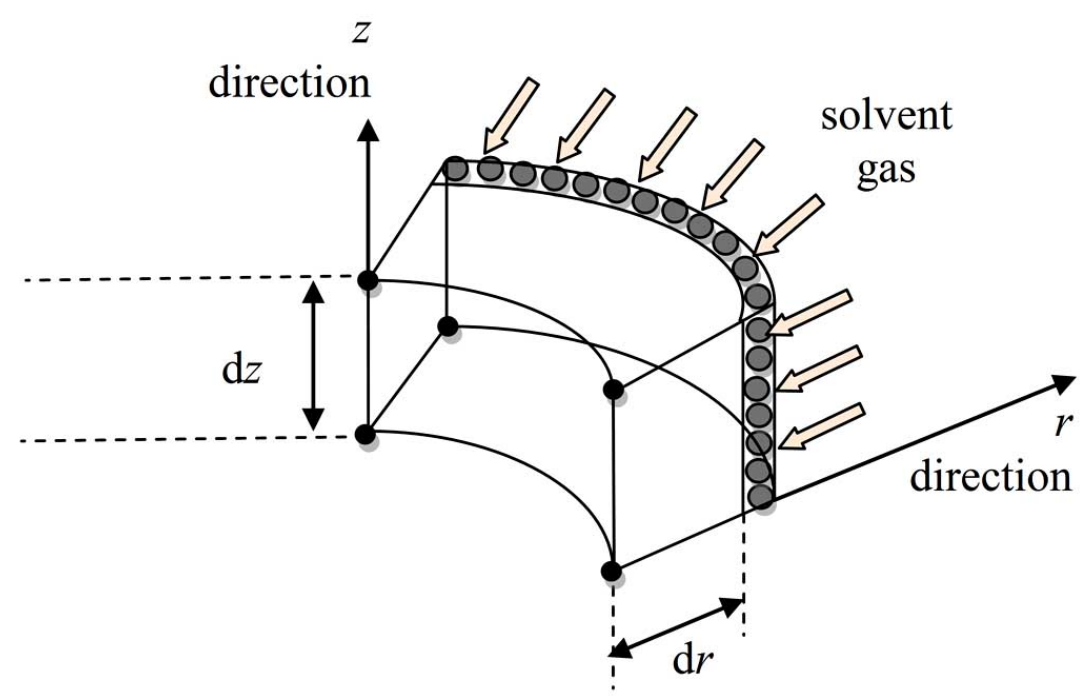

Fig. (2). Differential element of the physical model.

The rate of change of the height of the physical model along the radial direction is given by:

$$
\frac{\mathrm{d} Z}{\mathrm{~d} t}=-v_{0}(r)
$$

where $v_{0}(r)$ is the Darcy velocity of live oil at a given $r$, and averaged over the differential volume at the bottom of the packed medium where $z=0$. The cumulative mass of produced live oil at any time is then given by:

$m_{\text {cal }}(t)=2 \pi \rho \varphi \int_{0}^{R}\left[Z_{0}-Z(t)\right] r \mathrm{~d} r$

\section{Initial and Boundary Conditions}

Initially, the height of bitumen is that of the physical model, i.e. $Z_{0}$. The surface is at an interfacial concentration of butane at all times. Hence, the initial conditions at $t=0$ are

$\omega=\left\{\begin{array}{l}0 \quad \text { for } 0<z<Z_{0}, \text { and } 0 \leq r<R \\ \omega_{\text {int }} \text { at } z=0, Z_{0} \text { and } 0 \leq r \leq R ; \text { and at } r=R \text { and } 0 \leq z \leq Z_{0}\end{array}\right.$

$Z=Z_{0}$

The boundary conditions for $t \geq 0$ are

$\omega=\omega_{\text {int }}$ at $z=0, Z(r, t)$ and $0 \leq r \leq R$; and at $r=R$ and $0 \leq z \leq Z(r, t)$

where $Z(r, t)$ is the height of the bitumen in the porous medium at a given $r$ and $t$. Furthermore, because of symmetry

$\frac{\partial \omega}{\partial r}=0$ at $r=0$ and $0 \leq z \leq Z(r, t)$

\section{Solution of Process Model}

The mass balance given by Equation (9) was discretized by applying second order finite differences along $r$ and $z$ directions to obtain set of ordinary differential equations at each grid point. Further details may be found elsewhere [10].
The equations so obtained are very stiff. They were integrated using semi-implicit Bader-Deuflhard algorithm with adaptive step size control [11]. Analytical Jacobian was derived and used. The adequate numbers of grid points, $N_{\text {I }}$ and $N_{\mathrm{J}}$, were determined by repeatedly integrating the equations with increasing numbers of grid points until the change in the calculated mass of live oil became insignificant. The final numbers of grid points along the radial and vertical directions were 25 and 10, respectively. Table 1 lists the various parameters used to solve the process model.

\section{Dispersion Coefficient Determination}

The dispersion coefficient of butane in the porous medium is optimally determinable along with the unknown interfacial butane mass fraction $\left(\omega_{\text {int }}\right)$ by minimizing the difference between the calculated and experimental live oil production. The calculated oil production is given by Equation (11) subject to the process model, which incorporates the coefficient of $D$ (i.e. $D_{0}$ ), and $\omega_{\text {int }}$ as two optimization variables. Thus, it is desired to determine $D_{0}$ and $\omega_{\text {int }}$ by minimizing the following objective function:

$E=\sqrt{\frac{1}{N} \sum_{i=1}^{N}\left(m_{\mathrm{cal}, i}-m_{\mathrm{exp}, i}\right)^{2}}$

where $N$ is the number of experimental data points, and $i$ is the $i$-th experimental time instant.

It has to be noted that temperature and pressure conditions are same for Vapex experiments with physical models of different (drainage) heights. Thus, $\omega_{\text {int }}$ is common to all experiments. Therefore, the individual $D_{0} \mathrm{~s}$ for different physical models were simultaneously determined along with the common $\omega_{\text {int }}$. In other words, the objective function was the sum of $E$ for each model with 
Table 1. Parameters Used to Solve the Process Model

\begin{tabular}{|c|c|}
\hline Parameter & Value \\
\hline \hline dispersion coefficient $\left(D_{0}\right)$ & $2 \times 10^{-8}-12 \times 10^{-8} \mathrm{~m}^{2} / \mathrm{s}$ \\
\hline permeability $(K)$ & $1.09 \times 10^{-10} \mathrm{~m}^{2}$ \\
\hline relative permeability $\left(K_{\mathrm{r}}\right)$ & 1 \\
\hline radius of physical model $(R)$ & $3 \mathrm{~cm}$ \\
\hline final time & $5 \mathrm{~h}$ \\
\hline height of physical model $(Z)$ & $25,35,45 \mathrm{~cm}$ \\
\hline live oil viscosity $\left(\mu_{0}\right)$ & $1.17 \times 10^{-3} \mathrm{~Pa} . \mathrm{s}$ \\
\hline live oil density $(\rho)$ & $830 \mathrm{~kg} / \mathrm{m}^{3}$ \\
\hline porosity $(\phi)$ & 0.38 \\
\hline Tolerance on error for gradients & $0.5-0.9$ \\
\hline
\end{tabular}

respective coefficients of $D$, and one interfacial concentration as optimization variables. The optimization algorithm was accordingly programmed employing Davidson-Fletcher-Powell minimization method [11]. The gradient of an $E$ with respect to $D_{0}$ and $\omega_{\text {int }}$ was determined as follows:

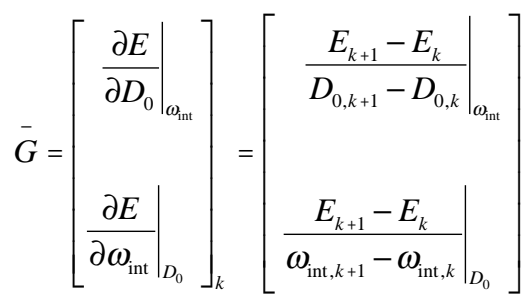

where $k \geq 0$ is the iteration counter, and $D_{0,0}$ and $\omega_{\text {int, } 0}$ are the initial guesses for $D_{0}$ and $\omega_{\text {int }}$, and

$D_{0, k+1}=D_{0, k}\left(1+10^{-4}\right)$

$\omega_{\mathrm{int}, k+1}=\omega_{\mathrm{int}, k}\left(1+10^{-4}\right)$

The resulting algorithm is computationally intensive because of the presence of a large number of stiff differential equations of all models, which should be solved to evaluate the objective function. When implemented on a 64-bit Itanium computer, the algorithm took over $12 \mathrm{~h}$ to converge depending upon the initial guess. The convergence was of the order $10^{-1}$.

\section{RESULTS AND DISCUSSION}

To investigate the effect of drainage height on oil production rates, Vapex experiments were carried out using four different heights of the physical model of $6 \mathrm{~cm}$ diameter. The heights were $15,25,35$ and $45 \mathrm{~cm}$. The experimental mass of live oil produced was determined using the load cell data. Fig. (3) shows cumulative live oil production for the four drainage heights. The rate of live oil production for any drainage height was more or less constant during a major part of production time. The production rate did not reduce significantly until $80-85 \%$ of the oil in the physical model had drained. For all drainage heights, there was no oil production from last $5 \mathrm{~cm}$ of the physical model.

The steady rate of live oil production is given by the slope of the dominant linear part of the production graphs in Fig. (3). That rate for $25 \mathrm{~cm}$ drainage height is $24 \%$ higher than that for $15 \mathrm{~cm}$ drainage height. The rate increases by $71 \%$ when the drainage height increases from 25 to $35 \mathrm{~cm}$. Almost the same percentage increase is observed when the height increases from 35 to $45 \mathrm{~cm}$. Thus, the rate of live oil production in Vapex is strongly dependent on drainage height. Based on these results, the steady rate of live oil production can be correlated as

$\dot{m}=1.26 \times 10^{-3} L^{1.496} \quad(\mathrm{~kg} / \mathrm{s})$

with the $r^{2}$ value of 0.993 . In the above equation, $L$ is the drainage height per unit diameter of the cylindrical physical model. This correlation agrees with the findings of Yazdani and Maini [5, 6] who experimentally determined the effect of drainage height on oil production rates in Vapex. They concluded that the stabilized oil production rate in Vapex is a function of drainage height raised to a power in the range, 1.1-1.3, which is close to the power of $L$ in Equation (20).

No significant effect of drainage height was observed on the measured viscosity and density of live oil, and the solvent solubility. Table 2 presents their values for different drainage heights.

Since temperature and pressure conditions were same for Vapex experiments with physical models of different (drainage) heights, the interfacial solvent mass fraction $\left(\omega_{\text {int }}\right)$ at the solvent-heavy oil interface (i.e. the surface of the physical model) should be the same. Therefore, the coefficients of $D$ for different physical models were 


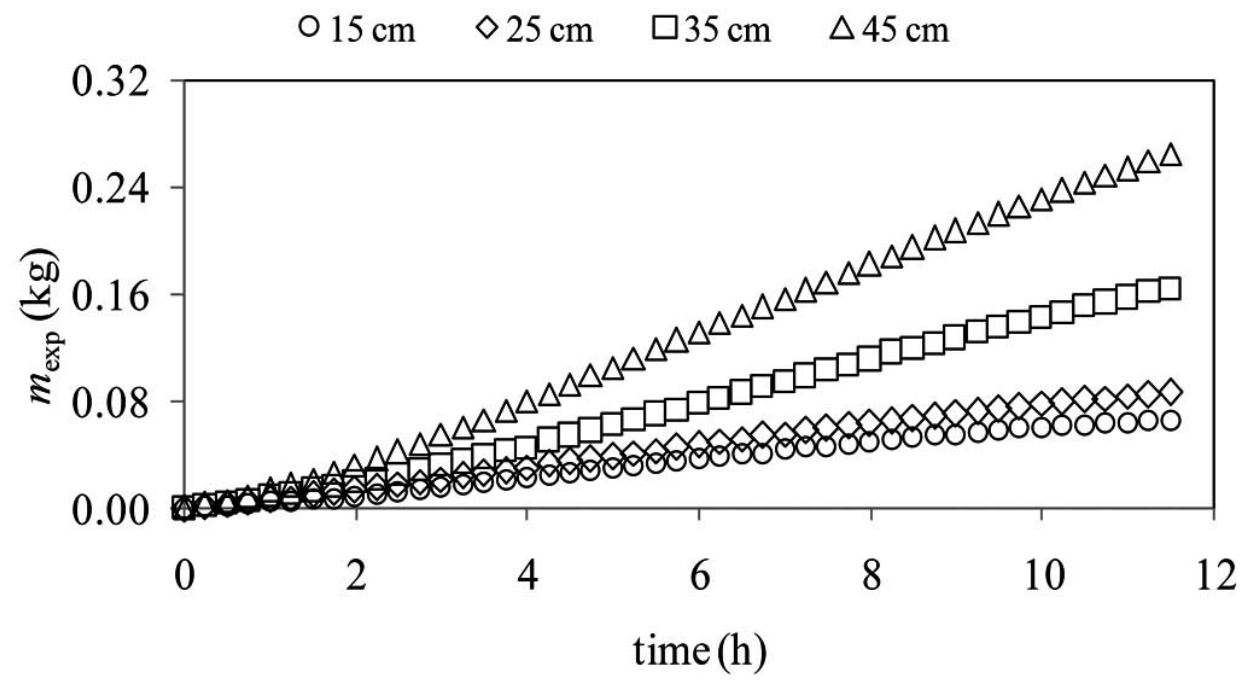

Fig. (3). Experimental cumulative live oil production for 15, 25, 35 and $45 \mathrm{~cm}$ drainage heights.

Table 2. Experimentally Determined Properties for Different Drainage Heights

\begin{tabular}{|c|c|c|c|}
\hline $\begin{array}{c}\text { Drainage Height } \\
(\mathbf{c m})\end{array}$ & $\begin{array}{c}\text { Solubility of Butane } \\
(\text { Mass Fraction) }\end{array}$ & $\begin{array}{c}\text { Live Oil Viscosity } \\
(\mathbf{c P})\end{array}$ & $\begin{array}{c}\text { Live Oil Density } \\
\left(\mathbf{k g} / \mathbf{m}^{\mathbf{3}}\right)\end{array}$ \\
\hline \hline 15 & 0.34 & 8.81 & 830 \\
\hline 35 & 0.35 & 9.07 & 800 \\
\hline 45 & 0.35 & 9.03 & 820 \\
\hline 45 & 0.34 & 9.00 & 820 \\
\hline
\end{tabular}

simultaneously determined with the common $\omega_{\text {int }}$ by minimizing the objective function. It was observed that solution of the model with this particular condition was very sensitive to initial guess of $\omega_{\text {int }}$.

In order to arrive at a good initial guess for $\omega_{\text {int }}$, the objective function $(E)$ was first minimized for each physical model with different initial values of $D_{0}$ (from $10^{-8}$ to $9 \times 10^{-8} \mathrm{~m}^{2} / \mathrm{s}$ ) and $\omega_{\text {int }}$ (from 0.5 to 0.9 ). Fig. (4) shows the resulting plot of $\omega_{\text {int }}$ at the minimum of $E$. As seen in the figure, there is a cluster of plot points with low $E$ and the lowest standard deviation in $\omega_{\text {int }}$ values. This cluster narrows down the range of choices for initial $\omega_{\text {int }}$ in the simultaneous
$\diamond 25 \mathrm{~cm}$
$\square 35 \mathrm{~cm}$
$\triangle 45 \mathrm{~cm}$

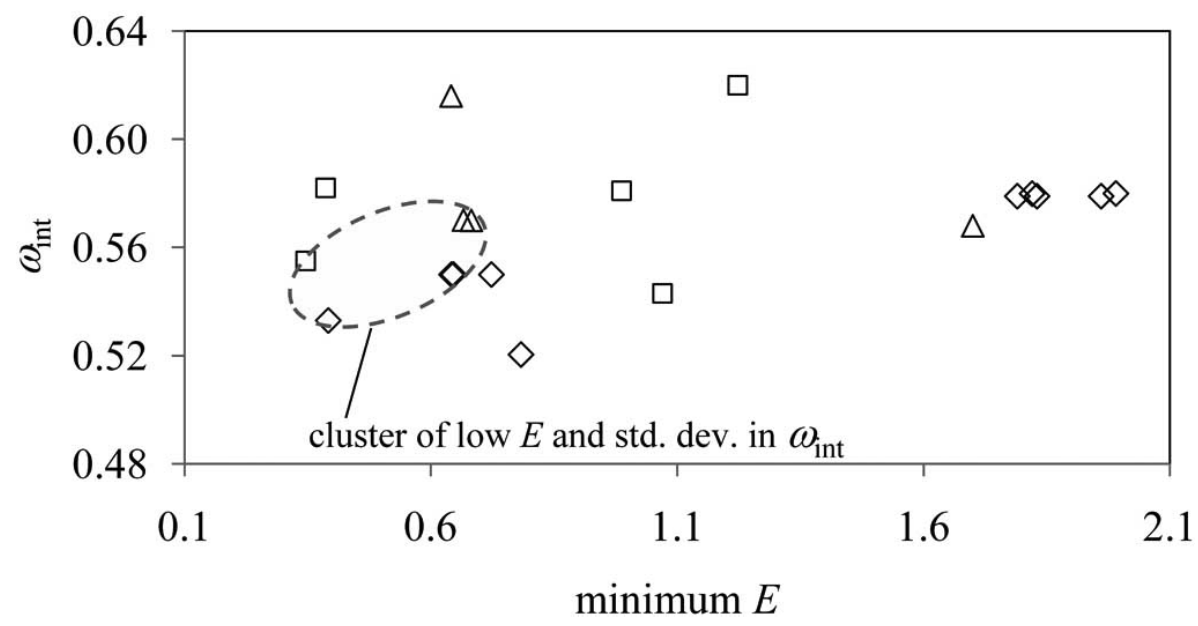

Fig. (4). Interfacial solvent mass fraction $\left(\omega_{\text {int }}\right)$ at the minimum objective function $(E)$ for 25,35 and $45 \mathrm{~cm}$ drainage heights. 


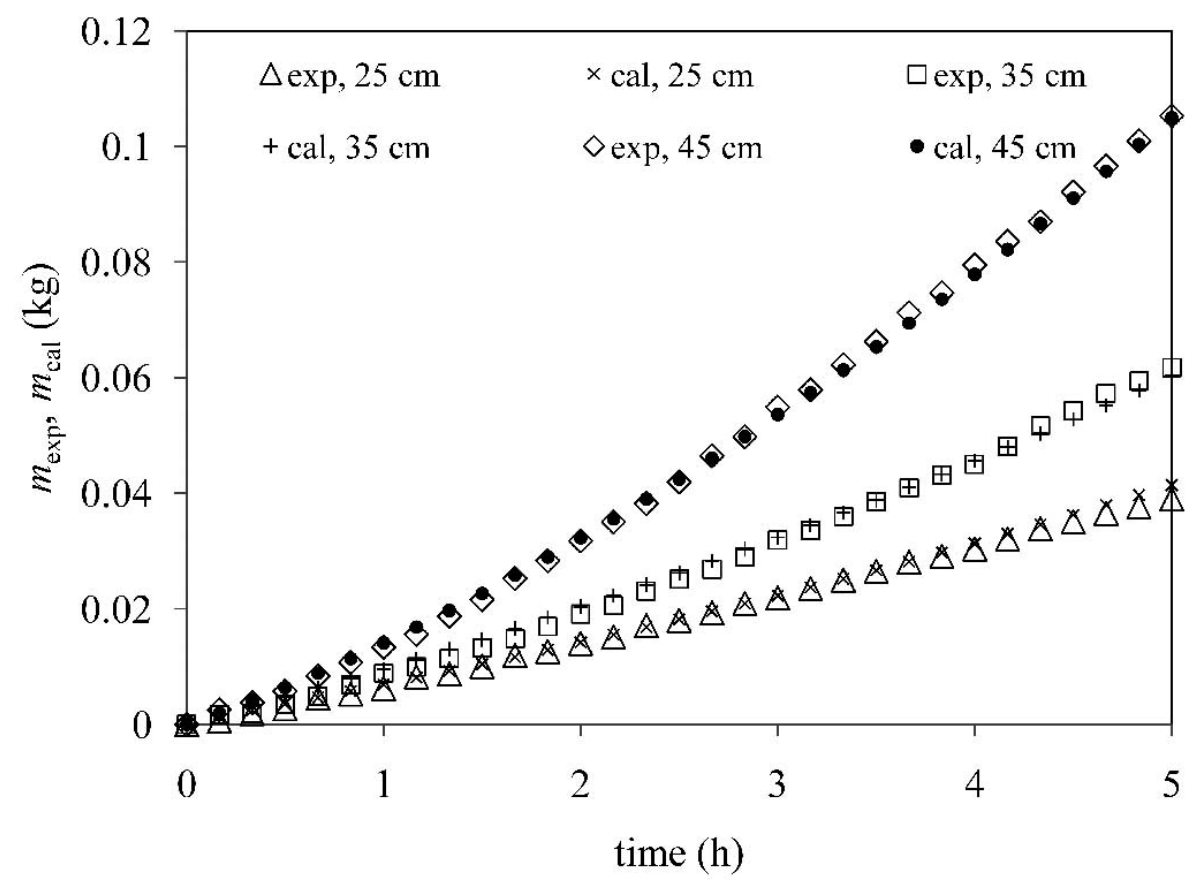

Fig. (5). Comparison of experimental live oil production with the calculated one corresponding to the optimal values of $\omega_{\text {int }}$ and $D_{0}$ listed in Table $\mathbf{3}$.

Table 3. Optimal $\omega_{\text {int }}$ and $D_{0}$ for the three Drainage Heights

\begin{tabular}{|c|c|c|c|}
\hline \multirow{2}{*}{$\begin{array}{c}\text { Drainage Height } \\
(\mathbf{c m})\end{array}$} & $\omega_{\mathrm{int}}$ & $\begin{array}{c}D_{0} \times 10^{8} \\
\left(\mathbf{m}^{2} / \mathbf{s e c}\right)\end{array}$ & Objective Function, $E$ \\
\hline \hline 25 & \multirow{2}{*}{0.557} & 3.21 & 0.67 \\
\cline { 1 - 2 } 35 & & 5.22 & 1.25 \\
\cline { 1 - 3 } & & 25.92 & 1.07 \\
\hline
\end{tabular}

optimization of all physical models. Based on the figure, the initial $\omega_{\text {int }}$ was selected between 0.53 and 0.57 .

Next, the algorithm was run with an initial guess of 0.55 for $\omega_{\text {sat }}$ and $1.0 \times 10^{-8} \mathrm{~m}^{2} / \mathrm{s}$ for $D_{0}$, to solve three models together. The optimal values of dispersion coefficient thus obtained were $3.21 \times 10^{-8} \omega, 5.22 \times 10^{-8} \omega$ and $25.92 \times 10^{-8} \omega$ $\left(\mathrm{m}^{2} / \mathrm{s}\right)$ with $\omega_{\text {sat }}=0.557$ and objective function values of $0.67,1.25$ and 1.07 for 25,35 and $45 \mathrm{~cm}$ model heights respectively. Fig. (5) shows the comparison between experimental and simulated values of live oil production obtained for the first 300 minutes of Vapex operation. The optimal coefficients of $D$ with objective function values are shown in Table 3.

The above results show that the coefficient of dispersion of butane increases with the drainage height. The minimum optimal value of dispersion coefficient obtained from this work corresponding to the shortest model length $(25 \mathrm{~cm})$ used is almost $67 \%$ lower than the dispersion coefficient of butane gas determined by El-Haj et al. [8] with model height of $21 \mathrm{~cm}$. The lower value of dispersion coefficient of butane obtained in this study may be attributed to the following: (i)
The viscosity of heavy oil used in this study is higher than used by El-Haj et al. [8], and (ii) The saturation mass fraction at solvent-oil interface in this work is lower than that in El-Haj et al. [8].

\section{CONCLUSIONS}

The concentration dependent dispersion coefficient of butane in vapor extraction of heavy oil and bitumen was determined with varying drainage heights. The experiments with cylindrical physical models were performed at constant temperature and dew point pressure of solvent (butane). The live oil production in Vapex was found to be a power function of drainage height almost three times higher than reported earlier. A computational algorithm was developed to simultaneously solve the multiple process models corresponding to different drainage heights and optimally determine the corresponding dispersion coefficients. It was found that dispersion coefficient of butane in this particular butane-heavy oil system is a strong function of drainage height. The dispersion coefficients (in $\mathrm{m}^{2} / \mathrm{s}$ ) were determined to be $3.21 \times 10^{-8}, 5.22 \times 10^{-8}$ and $25.92 \times 10^{-8}$ times the butane mass fraction respectively for 25,35 and $45 \mathrm{~cm}$ drainage heights. 


\section{NOMENCLATURE}

$D=$ Dispersion coefficient of butane in the medium, $\mathrm{m}^{2} / \mathrm{s}$

$D_{0} \quad=\quad D$ when $\omega=1, \mathrm{~m}^{2} / \mathrm{s}$

$E \quad=\quad$ Root-mean-square error given by Equation (13)

$G=$ Gradient for optimization

$G=$ Gravity, $9.81 \mathrm{~m} / \mathrm{s}^{2}$

$J \quad=$ Dispersive flux of butane in the medium along the radial direction, $\mathrm{kg} / \mathrm{m}^{2} \cdot \mathrm{s}$

$K=$ Permeability of the medium, Darcy

$K_{\mathrm{r}}=$ Relative permeability of the medium

$m_{\text {cal }}=$ Calculated mass of the produced live oil, $\mathrm{kg}$

$m_{\exp }=$ Experimental mass of the produced live oil, $\mathrm{kg}$

$N \quad=\quad$ Number of experimental data points

$N_{\mathrm{I}} \quad=\quad$ Number of grid points along the radial direction

$N_{\mathrm{J}} \quad=\quad$ Number of grid points along the axial direction

$R \quad=\quad$ Distance along the radial direction, $\mathrm{m}$

$R \quad=\quad$ Radius of cylindrical medium, $\mathrm{m}$

$T \quad=$ Time, $\mathrm{s}$

$V \quad=$ Darcy velocity, $\mathrm{m} / \mathrm{s}$

$Z=$ Distance along the axial, vertical direction, $\mathrm{m}$

$Z=$ Bitumen height in the medium at a given $r$ and $t, \mathrm{~m}$

$Z_{0} \quad=\quad$ Initial $Z, \mathrm{~m}$

\section{GREEK SYMBOLS}

$\phi \quad$ Porosity of the medium

$\mu \quad=\quad$ Viscosity of the live oil, $\mathrm{cP}$

$\mu_{0} \quad=$ Viscosity coefficient of the live oil, $\mathrm{cP}$

$\rho=\quad$ Density of the live oil, $\mathrm{kg} / \mathrm{m}^{3}$

$\omega=$ Mass fraction of butane in bitumen $\omega_{\mathrm{int}}=\omega$ at the butane-heavy oil interface

$\Delta A \quad=$ Area transverse to $v, \mathrm{~m}^{2}$

$\Delta r \quad=$ Intergrid distance along the radial direction, $\mathrm{m}$

$\Delta S \quad=$ Area transverse to $J, \mathrm{~m}^{2}$

$\Delta V=$ Volume of a finite element in the medium, $\mathrm{m}^{3}$

\section{REFERENCES}

[1] R. M. Butler, and I. J. Mokrys, "Solvent analog model of steam assisted gravity drainage", AOSTRA Journal, vol. 5, pp. 17-32, 1989.

[2] S. R. Upreti, A. Lohi, R. A. Kapadia, and R. El-Haj, "Vapor extraction of heavy oil and bitumen: a review", Energy Fuels, vol. 21, pp. 1562-1574, 2007.

[3] S. K. Das, and R. M. Butler, "Mechanism of the vapor extraction process for heavy oil and bitumen", Journal of Petroleum Science Engineering, vol. 21, pp. 43-59, 1998.

[4] A. Boustani, and B. B. Maini, "The role of diffusion and convective dispersion in vapour extraction process", Journal of Canadian Petroleum Technology, vol. 40, no. 4, pp. 68-77, 2001.

[5] J. A. Yazdani, and B. B. Maini, "Effect of drainage height and grain size on rates in the VAPEX process: Experimental Study", SPE Reservoir Evaluation \& Engineering, vol. 8, pp. 205-213. 2005.

[6] J. A. Yazdani, and B. B. Maini, "Further investigation of drainage height effect on production rate in Vapex", in SPE Annual Technical Conference and Exhibition, San Antonio, TX, USA, 2006, pp. 24-27.

[7] R. A. Kapadia, S. R. Upreti, A. Lohi, and I. Chatzis, "Determination of gas dispersion in vapor extraction of heavy oil and bitumen", Journal of Petroleum Science Engineering, vol. 51, pp. 214-222, 2006.

[8] R. El-Haj, A. Lohi and S. R. Upreti, "Experimental determination of butane dispersion in vapor extraction of heavy oil and bitumen", Journal of Petroleum Science Engineering, vol. 67, pp. 41-47, 2009.

[9] S. K. Das, and R. M. Butler, "Extraction of heavy oil and bitumen using solvent at reservoir pressure", in Sixth Petroleum Conference of the South Saskatchewan Section of Petroleum Society, Regina, SK, Canada, October 16-18, 1995.

[10] M. Imran, "Dispersion Coefficient Determination in Vapex Process”, M.Sc. thesis, Ryerson University, Toronto, ON, Canada, 2008.

[11] W. H. Press, S. A. Teukolsky, W. T. Vetterling, and B. P. Flannery, "Numerical recipes in C++", The Art of Scientific Computing, New York, USA: Cambridge University Press, 2nd ed. 2002, pp. 719727.

(C) Imran et al.; Licensee Bentham Open.

This is an open access article licensed under the terms of the Creative Commons Attribution Non-Commercial License (http://creativecommons.org/licenses/by-nc/3.0/) which permits unrestricted, non-commercial use, distribution and reproduction in any medium, provided the work is properly cited. 